\title{
Correspondence
}

\section{Cut food waste to help feed world}

Climate-proofing farms to help feed the world's expanding population needs to be complemented by global measures to cut food losses and waste (see Nature 523, 396-397; 2015).

Roughly one-third of the food produced annually for human consumption - around 1.3 billion tonnes per year - is lost or wasted worldwide (see M. M. Rutten Agric. Food Secur. 2, 13; 2013). In developing economies, more than $40 \%$ of food losses occur after harvesting or during processing (see go.nature.com/um7vga).

We should follow the lead of the Asia-Pacific economies, which have pledged to reduce food losses and waste by $10 \%$ relative to 2011-12 levels by 2020 (see go.nature.com/rfupkz). Don Gunasekera Victoria University, Melbourne, Australia. don.gunasekera@vu.edu.au

\section{Forgotten findings of brain lymphatics}

Antoine Louveau and colleagues describe lymphatic vessels in the central nervous system (Nature 523, 337-341; 2015), suggesting that "the unique location of these vessels may have impeded their discovery to date". However, these findings are not without precedent.

The first description of a lymphatic circulation in the head was soon forgotten (G. Schwalbe Z. Med. Wiss. 7, 465-467; 1869), as were other early landmark experiments (J.B. Brierley and E. J. Field J. Anat. 82, 153-166; 1948). These included half a dozen seminal contributions in the 1960s from a Hungarian group led by the late neurologist Endre Csanda and lymphologist Mihaly Földi.

This group of researchers described the existence and significance of a lymphatic system in the central nervous system, stating that "in striking contrast to the textbook opinion, lymph drainage plays an important part in fluid circulation of the brain". They identified "welldefined connections between the subarachnoid space and the cervical lymph system in the nasal cavity, in the orbita and in the region of the jugular foramen" (M. Földi et al. Angiologica 5, 250-262; 1968).

Perhaps old papers that are not available as online PDFs are easily overlooked in today's literature searches, depriving many of our scientific predecessors of the recognition they deserve. Éva Mezey National Institute of Dental and Craniofacial Research, Bethesda, Maryland, USA.

Miklós Palkovits Semmelweis University, Budapest, Hungary. mezeye@nidcr.nih.gov

\section{Lifelong learning for all in biomedicine}

Cross-disciplinary and team-based modern research is overwhelming established mechanisms for maintaining professional competency. This calls for a change to personnel training that is not limited to professors (see C. E. Leiserson and C. McVinney Nature 523, 279-281; 2015).

The European Innovative Medicines Initiative projects on education and training aim to promote lifelong learning and continuing professional development among all biomedical professionals (see go.nature.com/enhijn). We are working with employers, professional and scientific bodies, course providers and individual scientists to develop a framework for implementing this cultural change, known as LifeTrain (see M. Hardman et al. Nature Rev. Drug Disc. 12, 407-408; 2013).

By providing guidance and information, we help them to recognize the competencies that they will need as their careers progress. We also encourage scientists to think beyond traditional disciplinary silos.

Several organizations and individuals have formally signed up to the agreed principles and implementation of LifeTrain; other prospective participants can contact us at www.lifetrain.eu. Cath Brooksbank, Claire Johnson EMBL-European Bioinformatics Institute, Hinxton, Cambridge, UK. cath@ebi.ac.uk

\section{Physicist's death changed war policy}

Just over 100 years ago, on 10 August, the 27-year-old British physicist Henry Moseley was killed in the First World War at the battle of Gallipoli. His work on the X-ray spectra of atoms had already explained the basis of Dmitri Mendeleev's periodic table of the elements, laying the foundations for the interpretation of chemistry through atomic structure.

Ernest Rutherford, who discovered the atomic nucleus, wrote an obituary of Moseley (Nature 96, 33-34; 1915) that may have helped to permanently change government policy on enlisting prominent scientists for combat duty. Even in the heat of war, Germany, too, lamented Moseley's death, such was his contribution to science (K. Fajans Die Naturwissenschaften 4, 381-382; 1916).

Min-Liang Wong National Chung-Hsing University, Taiwan. mlwong@dragon.nchu.edu.tw

\section{Offsets: conservation served by flexibility}

The debate over whether national protected areas are eligible for biodiversity-offset funding should factor in the different challenges and contexts for countries seeking to conserve their biodiversity (see M. Maron et al. Nature 523, 401-403; 2015).

Offsets that are voluntary (such as those of the mining

companies Minera Panamá and QIT Madagascar Minerals; see also go.nature.com/zxvlet) are a source of extra conservation funding. This is analogous to grants from foundations or from the Global Environment Facility, which are considered a legitimate way to finance fulfilment of the Aichi biodiversity targets (see go.nature.com/avssmr).

In countries where offsets or compensation payments are required by law or lender standards, they serve as a tax on environmental impacts. This follows the accepted 'polluter pays' taxation model, and has the benefit of earmarking the revenue for conservation.

In heavily populated regions, the only socially acceptable place to implement offsets might be in protected areas selected by public processes. In such settings, offsets and protected areas would need to be closely linked.

Excluding offsets or compensation from financing of protected areas would affect developing countries, most of which struggle to finance such areas. It would, for example, exclude all of Brazil's protectedareas system from contributing to Aichi Target 11, because compensation is integral to the country's law on protected areas. Jared J. Hardner Hardner \& Gullison Associates, Amherst, New Hampshire, USA.

Raymond E. Gullison Hardner \& Gullison Associates, Lantzville, British Columbia, Canada; and University of British Columbia, Vancouver, Canada. Porter P. Lowry II Missouri Botanical Garden, St Louis, Missouri, USA. ted@hg-llc.com

CONTRIBUTIONS

Correspondence may be submitted to correspondence@nature. com after consulting the author guidelines at http://go.nature.com/ cmchno 